\title{
Electrical Power Generation System: Optimal Design for Medium-Load Industries with High-Rated Generators
}

\author{
Md. Janibul Alam Soeb, Md. Shahid Iqbal, Md. Abu Naser Mojumder, \\ Muhammad Rashed Al Mamun, A. S. M. Shahjalal Atik, and Md. Fahad Jubayer
}

\begin{abstract}
The demand for electrical power is rapidly increasing due to the rise of industries in developing countries. Power generation stations are having troubles to strike a balance between demand and generation. In this situation, it is urged that appropriate remedial action be taken. Rising power demand can be met by designing an efficient electric power generation system which will also help lowering the generation cost. It is shown that while high rated electric power generators are connected in parallel the value of neutral current is rising and the cooling temperature is also increased. Here, the goal of this experimental work is to present a new model for designing an efficient power production system for average-load (ranging up to $8000 \mathrm{Amp}, 440 \mathrm{~V}$ ) industries to minimize the demand on centralized interconnected grid. A scheme is proposed with four generators $(2500 \mathrm{kVA}, 2000 \mathrm{kVA}, 2000 \mathrm{kVA}$ and $1250 \mathrm{KVA})$ in parallel and enough cooling arrangement is provided with minimal cost. The coolant temperature is maintained $61{ }^{\circ} \mathrm{C}$ to $61.5^{\circ} \mathrm{C}$ and at that time diesel temperature is not more than 38.5 ${ }^{\circ} \mathrm{C}$. The amount of neutral-current is also optimized (up to 8.5 Amp.) which was more than 12 Amp. At the morning and afternoon, the neutral current is almost constant, but it is bit fluctuating between 7.5 Amp to $8.2 \mathrm{Amp}$ at mid-day. The final outcome shows, the suggested system is efficiently stable with the change of load and generates optimal electricity.
\end{abstract}

Keywords - distributed generation, generators, load conditions, medium load industry, power generation optimization.

\section{INTRODUCTION}

The power system is the most complicated system in modern life, with direct implications for modernization, economics, politics, and social issues [1]. Electric power networks have a variety of obstacles, including less efficient, higher energy waste, high pollutants, and a significant risk of economic power abuse [2]. The gap between wholesale energy market pricing and retail tariffs in typical flat electricity tariffs leads to inefficient resource utilization since consumers are not incentivized to change their usage according to supply prices [3]-[8]. Furthermore, demand in electric power networks has a high peak to average ratio (PAR) [9]-[11]. As the peak hours are only a minimum

Submitted on December 01, 2021

Published on December 23, 2021.

M. J. A. Soeb, Department of Farm Power and Machinery, Sylhet Agricultural University, Bangladesh

(e-mail: janibul.fpm ${ }^{\circledR}$ sau.ac.bd)

M. S. Iqbal, Department of Electrical and Electronic Engineering, Sylhet Engineering College, Bangladesh.

(e-mail: shahidiqbal_05@yahoo.com)

M. A. N. Mojumder, Department of Computer Science and Engineering,

Sylhet Engineering College, Bangladesh.

(e-mail: abu.naser84@gmail.com) number of hours per day, substantial investments in generation, transmission, and distribution systems are required to meet peak demand, resulting in higher power generating and electric power supply costs [2].

As the developing third world countries are marching forward to become developed nations, power demand is rapidly increasing due to the high rate of industrialization. Many industries in developing countries like Bangladesh have land shortage and the power crisis is a concern for its growth [12]. Efficient power generation system can help industries by lowering the generation and transmission cost of electrical power which also helps these industries to maximize their production capabilities. Designing such an efficient power system is the most important step in this direction. The demand, or the amount of power consumed in $\mathrm{KW}$, is always taken into account in the design.

Climate change has major influence on the power grid. The whole world is facing various kinds of natural calamities due to climate change which affect power systems on many different levels, including transmission and distribution [13] Various power generation methods are presented, and some solutions are quite efficient. This is a significant shift in power system architecture, which has hitherto relied on massive, concentrated power plants. Problems arise when renewable energy sources are used as supplementary support for a power system since the sources are not easily available. Because renewable power generation technologies must coexist with existing power systems, integration issues arise. Increased use of distributed generation (DG) units, which include both renewable and non-renewable power sources like photovoltaic (PV) or solar, wind turbines, wave generators, fuel cells, and gas/steam powered Combined Heat and Power (CHP) stations, is being driven by a drop in inflation (and thus increase in cost) of fossil fuels, rising demand for electricity, and government policies aimed at reducing greenhouse gas emissions [12]. Bangladesh, like other countries, is eager to enhance its power infrastructure by utilizing renewable energy sources. However, in order to meet the power demand, competent generating technologies must be used, with the ability to mitigate the aforementioned issues.

M. R. Al Mamun, Department of Farm Power and Machinery, Sylhet Agricultural University, Bangladesh.

(e-mail: rashed.fpm ${ }^{\circledR}$ sau.ac.bd)

A. S. M. S. Atik, Department of Electrical and Electronic Engineering, Sylhet Engineering College, Bangladesh.

(e-mail: atik.shahjalal@gmail.com)

M. F. Jubayer, Department of Food Engineering and Technology, Sylhet Agricultural University, Bangladesh.

(e-mail: jubayer.fet ${ }^{@}$ sau.ac.bd) 
The increased demand for electricity, on the other hand, necessitates changes to the existing power generation system. It has already been demonstrated that when high-rated generators are coupled in parallel, the neutral current increases rapidly and becomes difficult to manage, as well as the temperature. At previous set up the neutral current was 12 Amp. and while the set up was running for long time the neutral current was more than that [11]. Hence, this current study was aimed to design a reliable and efficient power generation scheme with a view to minimize the neutral current and the temperature of the centralized interconnected generators and generate electrical power with cost minimization.

\section{Problems With The CURRENT Power System AND PROPOSED SOLUTION}

\section{A. Limitations of Existing Power Systems}

There are a number of constraints with power systems. The power situation is worsening by the day as a result of these limits. The primary drawbacks of current power systems can be described as follows [12], [14]:

\section{1) Ineffectiveness}

Approximately $8 \%$ of total generated electricity is lost via transmission grid lines, and $20 \%$ of the capability of power generation is available to satisfy peak demand. The efficiency is low due to the considerable transmission loss. Other losses in the present power system exist in addition to transmission losses. The current power grid is inefficient in this regard.

\section{2) Failures of Domino - Effect}

It's a hierarchical arrangement in which power plants at the top make sure power gets to customers' loads at the bottom. In short, power is only transmitted in one way, resulting in large-scale blackouts due to power plant failures or transmission line problems. The most well-known power outage in Bangladesh happened in November 2014, when cascading incidents caused 100 million out of 160 million customers to lose power for 10 hours [18], [19].

The following data was collected for a $2500 \mathrm{kVA}$ generator:

Manufacturing Year: 2011.

Power Rating: $2500 \mathrm{kVA}$.

Current Rating: 3609 amp.

Voltage Ratio: 400/230.

RPM: 1500.

Temperature (Maximum): $30^{\circ} \mathrm{C}$.

Voltage of excitation: $47 \mathrm{~V}$.

Essential current for excitation: 5 amp.

The design of the system is represented by Fig. 1.

\section{3) Destabilization}

System stability is being harmed by unusual fluctuations in demand for electrical power, as well as increasing DG penetration and lagging expenditures in electrical power facilities. Power generation systems are forced to run at the commencement of oscillation due to load demand and a lack of transmission capability. Low frequency electromechanical oscillations caused by unbalanced mechanical torques owing to perturbations (load and topology fluctuations) can impede power sharing between areas and lead to load shedding if they are not adequately reduced [15], [16]. As a result, a model is designed for an efficient power system to match the consumers' power consumption demand [4]. The model of an efficient power generation system is addressed in detail in the next paragraphs, and then the focus of this work is on the obstacles of constructing such a system. We use a reference model for this, which is discussed in the next section.

\section{B. System Architecture}

The model is designed for medium-load industries in Bangladesh that use high-rated (KVA) generators. The generators in the proposed system are rated at $1250 \mathrm{kVA}$, $2000 \mathrm{kVA}, 2000 \mathrm{kVA}$, and $2500 \mathrm{kVA}$, respectively. These four generators have four separate exhaust system, but they are sharing a common fuel tank and a common storage tank. All the generators are wired to maintain parallel connection. Every generator can be controlled separately. There are some mechanisms are also maintained to reduce the vibrations of these generators.

The system design is shown below in Fig. 1.

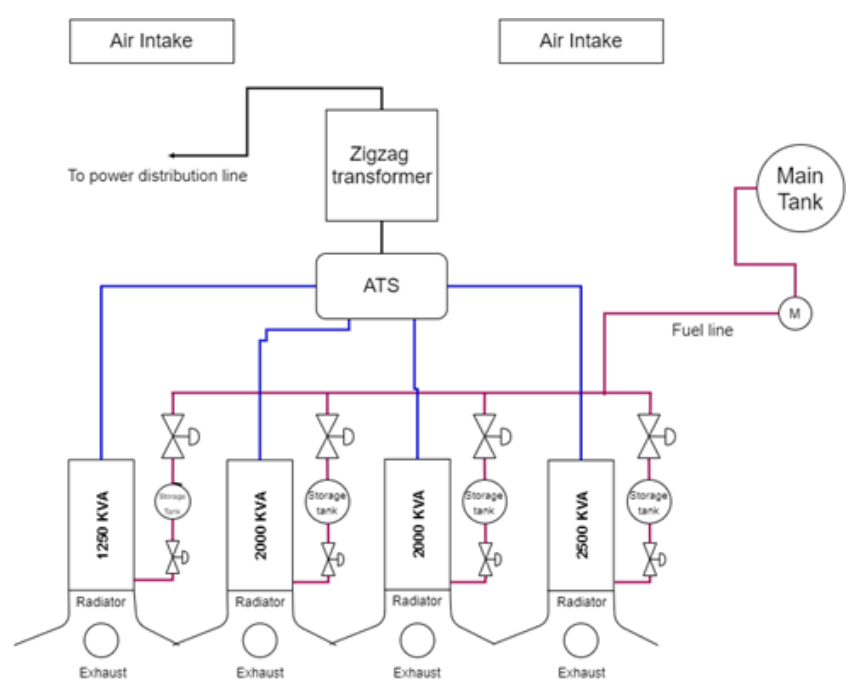

Fig. 1. Proposed model for power generation system.

The proposed approach maximizes the utilization of area and equipment for a more efficient power production system for medium-load industries that require 5 or $6 \mathrm{MW}$. This model includes a few unique features, which are detailed in the subsections below.

\section{1) Compact Shape}

In most cases, medium load industries have limited space for electrical power generation. So, the first priority of the design is to address the space shortage and designing a system that can be built in compact spaces. A compact space system is essential for reducing land size, as well as making power generation more cost-effective and efficient.

\section{2) Shorter distance between generation and load}

According to the distance rule of resistance, wire resistance increases as the distance between a generating station and a load center increases, resulting in transmission loss. Because the generation and load centers in this proposed system are so close together, power loss is greatly reduced. As a result, the most efficient and effective power generation and distribution are achievable. 


\section{3) Cost savings on conductors}

Transmission networks lose about $8 \%$ of total generated electricity, and only one-fifth of total generation capacity is available to meet peak demand. Because of the significant transmission loss, the efficiency is low. In addition to transmission losses, there are other losses in the current power system. In this aspect, the current electrical grid is inefficient.

\section{4) Minimization of heat and excess noise}

For human safety, an appropriate heat and noise margin level must be maintained for a 6.2 MW power generating station. To keep noise levels between 85 and $95 \mathrm{~dB}$, a silencer box is used. Heat reduction is achieved by radiators and exhaust pipes.

\section{5) Air intake and exhaust properly}

The total air requirement for four generators exceeds $7,00,000 \mathrm{~cm}^{3}$. To meet the demand for needed air, a centrifugal blower system is created to be installed at the front side of the chamber. To accomplish the needed level of air intake, high-pressure blowers are used. The system has four exhaust pipes and three blowers on the back side to move exhaust and heated air outside of the space.

\section{6) Size reduction of fuel tank}

The temperature of the generator's inlet should never exceed $40^{\circ} \mathrm{C}$. For cooling, a heat exchanger is employed in this model. The cooling system is attached to the generator's return fuel $(200 \mathrm{~L})$ line to cool the fuel when it reaches temperatures above $60^{\circ} \mathrm{C}$. As a result, the heat is absorbed by the water in the cooling system, and fuel from the return line returns to the tank at its optimal temperature, which is below $40{ }^{\circ} \mathrm{C}$. When the fuel level in the storage tanks falls below a certain threshold, fuel flows from the main tank to the storage tanks.

\section{Methodology}

An outline of the system has been presented below, as per the proposed model:

\section{1) Generator Arrangement}

The generators are connected parallelly and installed 10inch-high from ground level. The spacing provided for four different generators are 7 feet, 10 feet, 14.5 feet, respectively. In running condition, generator creates vibration which is a potential cause of problems in the system. To remove this occurrence some concrete is laid directly on the top of the floor slab and the generators are mounted on the concrete pad. This concrete pad provides easy cleaning facility around the generators and a strong base level.

\section{2) Air Intake/Outlet}

In this model the combustion air inlet flow rate for the $2500 \mathrm{kVA}, 2000 \mathrm{kVA}$ and $1250 \mathrm{kVA}$ generators are 7500 CFM, 4400 CFM, 3200 CFM, respectively. The high compressed air maintains a constant temperature. 10 exhaust fans are used to release exhaust air in the environment after circulation.

\section{3) Louver system}

The Louver system is installed on the right side of the generator, allowing air to circulate freely. It has a height of 15 feet and a length of 24 feet. This method keeps the generating area cool while also reducing noise.

\section{4) Setup of the fuel tank}

The main diesel supply tank is located at the outer part of generator room and is linked to each generator's storage tanks. The main diesel tank has a net capacity of $90,000 \mathrm{~L}$ and is made up of four interconnected tanks. Each generator is equipped with its own storage tank. The storage tanks for the $2500 \mathrm{kVA}, 2000 \mathrm{kVA}$, and $1250 \mathrm{kVA}$ generators have capacities of 5800, 4200, and $2600 \mathrm{~L}$, respectively. The diesel is pulled to the storage tanks and the pipes which are surrounded by motors. Two accessories are utilized at the generator fuel inlets: a control valve and a pressure gauge. Along with the motor, a control valve, a pressure gauge, and a meter are installed. The meter displays the amount of fuel flowing through the pipe, the flow control valve regulates diesel flow, and the pressure gauge measures pressure in the tank and inside the pipe. Hand valves are also utilized for maintenance and versatility.

Through the fuel return line, which is connected to the heat exchanger that cools the oil, any surplus diesel is returned to the storage tank. To keep track of the temperature, two thermometers are attached on both sides of the storage tanks.

\section{5) System of exhaust}

There are four cycles in a diesel engine. After a complete cycle of a diesel engine, each generator produces hot exhaust gas, which flows to the exhaust system. This system's goal is to safely release the combustion product known as exhaust gas into the outside atmosphere while posing the least amount of risk to people and the environment. The piping system, which originates from the silencer pipe, is installed 20 feet above ground level on the generator room's roof. Four flexible pipes are used to connect four generators. Back pressure is not a problem because the exhaust pipe is large enough. Exhaust pipes are insulated to minimize operator burns and reduce radiant heat loss.

\section{6) Heat exchangers}

Heat exchangers are used to release the heat generated by the engine into the atmosphere. The heat exchanger is not directly attached to the engine; instead, it is attached to the generator set. Electric fans deliver cooling air to the close heat exchangers, which are positioned vertically.

\section{7) Firefighting Systems and Equipment}

Firefighting equipment is necessary in the generator room. Ten cylinders of $\mathrm{CO}_{2}$ extinguishers are provided in the room. Where the exhaust pipe goes through the building, fireresistant materials are employed. Ear plugs, ear muffs, and maintenance tools are provided to those working in the room.

\section{8) Minimization of heat and excess noise}

Each generator has a silencer installed to reduce engine noise. It is located on the engine's upper side. Here, strict adherence to municipal noise ordinances is required at all times. For heat removal, dry type insulation is employed over the silencer and exhaust pipe. To keep the generator room cool, adequate air movement is maintained. This is accomplished through the employment of a cooling system and exhaust fans.

\section{9) Utility of energy}

It is important to make all the equipment function properly. 
Utility energy must be used to energized important components while generators are not working. The generators' set components are maintained and started using battery chargers, turbo chargers, space heaters, and other devices.

\section{0) Neutral Current Compensation}

As all the loads in the connected system has to be provided a neutral point, 3 phase 4 wire scheme is followed in this case. The majority of these loads are unbalanced, resulting in high neutral current at both fundamental and harmonic frequencies [20]. The neutral conductor's zero-sequence current is three times greater than the zero-sequence current of each phase. Additionally, unbalanced load currents pass via the neutral conductor with zero sequence components. The Zigzag transformer was developed to correct for neutral current and zero sequence harmonic current [22]. A Zigzag transformer handles the neutral current compensation of the three-phase four-wire distribution network. The windings of the Zigzag transformers are constructed in such a way that the MMFs cancel out, resulting in neutral current compensation [23]. This analysis used a $250 \mathrm{kVA}$ three-phase zigzag transformer with a rated primary voltage of $11 \mathrm{kV}$ and a rated secondary voltage of $440 \mathrm{~V}$.

\section{RESULTS}

The electrical power for three phase system can be described by the following equation:

$$
\mathrm{P}=\sqrt{3} \mathrm{VI} \cos \phi
$$

where $\mathrm{V}=$ Three phase line voltage, $\mathrm{I}=$ Three phase line current and $\cos \phi=$ Power factor. At the morning (8:30-9:30 a.m.) when the industry starts to run, data of voltage, current and power are recorded. This is described in Table I.

TABLE I: EXPERIMENTAL DATA OF THE SYSTEM FROM 8.30 - 9.30 A.M.

\begin{tabular}{|c|c|c|c|c|c|c|}
\hline $\begin{array}{l}\text { Starting } \\
\text { time }\end{array}$ & $\begin{array}{c}\text { Ending } \\
\text { time }\end{array}$ & $\begin{array}{l}\text { Total } \\
\text { time }\end{array}$ & $\begin{array}{c}\text { Avg. } \\
\text { Voltage (V) }\end{array}$ & $\begin{array}{c}\text { Avg. } \\
\text { Current (A) }\end{array}$ & $\cos \phi$ & $\begin{array}{l}\text { Power } \\
(\mathrm{KW})\end{array}$ \\
\hline $\begin{array}{l}8.30 \\
\text { a.m. }\end{array}$ & $\begin{array}{l}9.30 \\
\text { a.m. }\end{array}$ & 1 & $\begin{array}{l}430 \\
430 \\
432 \\
432 \\
432 \\
435 \\
435 \\
438 \\
440 \\
442 \\
\end{array}$ & $\begin{array}{c}5841.17 \\
6311.5 \\
7115.4 \\
7180.2 \\
7188 \\
7193.37 \\
7208.7 \\
7223 \\
7230.34 \\
7232.06 \\
\end{array}$ & $\begin{array}{c}0.81 \\
0.835 \\
0.851 \\
0.876 \\
0.88 \\
0.884 \\
0.873 \\
0.864 \\
0.881 \\
0.897 \\
\end{array}$ & $\begin{array}{l}3524 \\
3925 \\
4531 \\
4706 \\
4733 \\
4791 \\
4741 \\
4734 \\
4854 \\
4966 \\
\end{array}$ \\
\hline $\begin{array}{l}\text { TAF } \\
\text { Starting } \\
\text { time }\end{array}$ & $\begin{array}{c}\text { E II: EXI } \\
\text { Ending } \\
\text { time }\end{array}$ & $\begin{array}{l}\text { Total } \\
\text { time }\end{array}$ & $\begin{array}{c}\text { DATA OF THI } \\
\text { Avg. } \\
\text { Voltage }(\mathrm{V})\end{array}$ & $\begin{array}{l}\text { YSTEM FROM } \\
\text { Avg. } \\
\text { Current (A) }\end{array}$ & $\frac{30-2 .}{\cos \phi}$ & $\begin{array}{l}\text { PM } \\
\text { Power } \\
(\mathrm{KW})\end{array}$ \\
\hline $\begin{array}{l}1.30 \\
\text { p.m. }\end{array}$ & $\begin{array}{l}2.30 \\
\text { p.m. }\end{array}$ & 1 & $\begin{array}{l}432 \\
430 \\
434 \\
435 \\
435 \\
439 \\
441 \\
445 \\
442 \\
443 \\
442 \\
441 \\
440 \\
\end{array}$ & $\begin{array}{c}7086.65 \\
7066.3 \\
7107 \\
7189.41 \\
7287.45 \\
7372.15 \\
7430 \\
7554.27 \\
7544.76 \\
7491.29 \\
7512 \\
7546.47 \\
7557\end{array}$ & $\begin{array}{c}0.89 \\
0.887 \\
0.89 \\
0.92 \\
0.91 \\
0.92 \\
0.92 \\
0.91 \\
0.9 \\
0.92 \\
0.93 \\
0.93 \\
0.93\end{array}$ & $\begin{array}{l}4719 \\
4690 \\
4755 \\
4983 \\
4996 \\
5157 \\
5221 \\
5298 \\
5198 \\
5288 \\
5248 \\
5361 \\
5356\end{array}$ \\
\hline
\end{tabular}

At noon (1:30-2:30 p.m.) data of voltage, current and power are recorded. Table II shows that recorded data at noon.

Finally, at the afternoon (3:30-4:30 pm) data of voltage, current and power are recorded. Recorded data is shown in Table III.

TABLE III: EXPERIMENTAL DATA OF THE SYSTEM FROM 3.30 - 4.30 P.M.

\begin{tabular}{ccccccc}
$\begin{array}{c}\text { Starting } \\
\text { time }\end{array}$ & $\begin{array}{c}\text { Ending } \\
\text { time }\end{array}$ & $\begin{array}{c}\text { Total } \\
\text { time }\end{array}$ & $\begin{array}{c}\text { Avg. } \\
\text { Voltage }(\mathrm{V})\end{array}$ & $\begin{array}{c}\text { Avg. } \\
\text { Current (A) }\end{array}$ & cos $\phi$ & $\begin{array}{c}\text { Power } \\
(\mathrm{KW})\end{array}$ \\
\hline & & & 435 & 7346.45 & 0.91 & 5064 \\
& & & 436 & 7412.7 & 0.91 & 5094 \\
& & & 439 & 7482.81 & 0.92 & 5234 \\
3.30 & 4.30 & & 442 & 7514.35 & 0.9 & 5177 \\
p.m. & p.m. & 447 & 7582 & 0.89 & 5224 \\
& & & 449 & 7559.62 & 0.88 & 5173 \\
& & & 446 & 7553 & 0.9 & 5251 \\
& & & 447 & 7604.31 & 0.91 & 5357 \\
& & & 446 & 7611.2 & 0.93 & 5468 \\
& & & & 7620.3 & 0.95 & 5580 \\
\hline
\end{tabular}

The outcome of the experiment shows that the temperature of coolant (C.T.) and the temperature of diesel (D.T.) are not changed significantly. The C.T. was maintained to keep between $61{ }^{\circ} \mathrm{C}$ to $62{ }^{\circ} \mathrm{C}$ temperature and the D.T. was maintained in between $36^{\circ} \mathrm{C}$ to $38.6{ }^{\circ} \mathrm{C}$ temperature. The figures are divided into two parts to describe. Three figures (Fig. 2, 3 and 4) explain the reaction of variation of C.T. and D.T. with Load in the first part, and three figures (Fig. 5, 6 and 7) describe the change of neutral current with the change of Load in the second part. The graphs are displayed below.

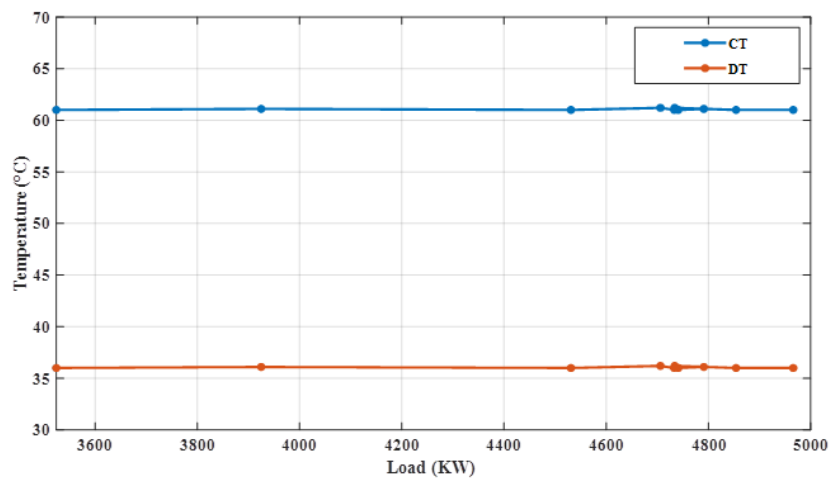

(a)

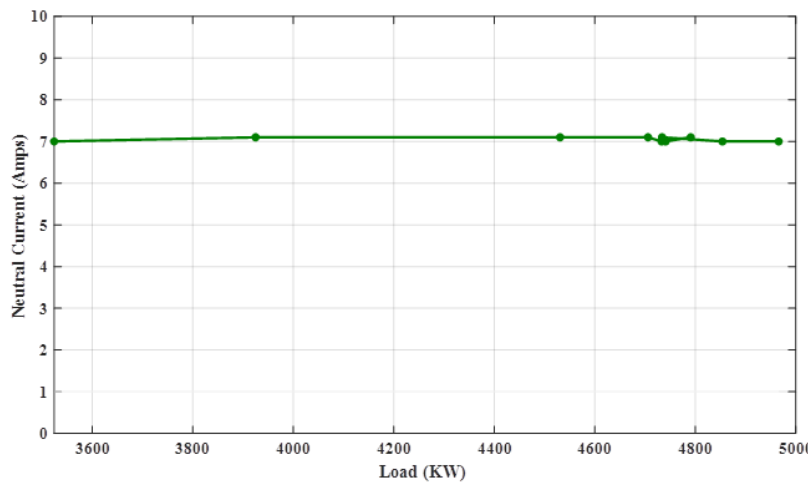

(b)

Fig. 2. This is a figure showing parameters like CT, DT, and NC from 8.30 am to 9.30 am (a) Variation of CT and DT with load; (b) Variations of NC with load

At the morning time, it is observed that the C.T. and D.T. are almost constant at our set up. The coolant and oil levels are in correct level and all the generators are placed at wellventilated area. So, the temperatures cannot exceed. 


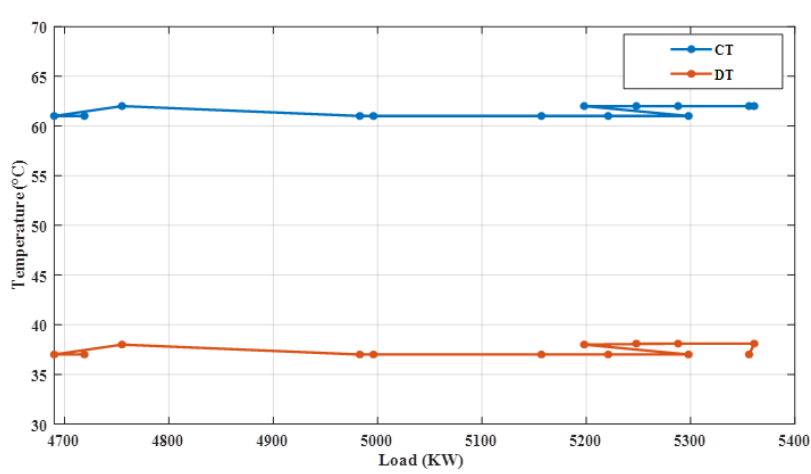

(a)

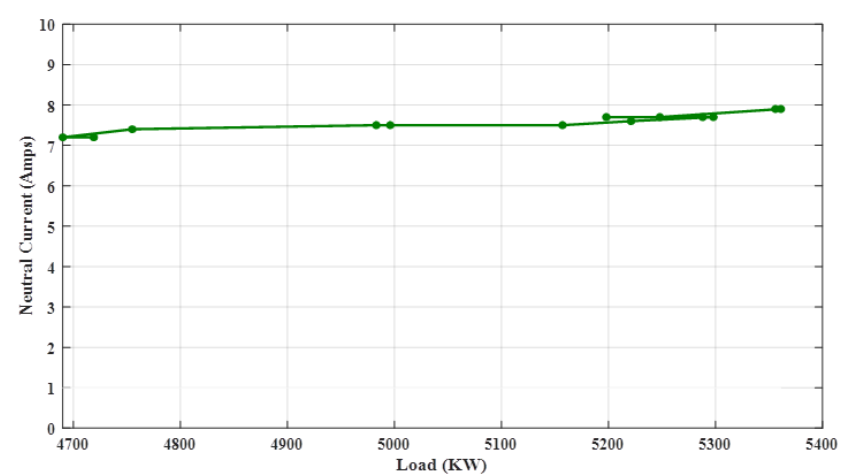

(b)

Fig. 3. This is a figure showing parameters like CT, DT, and NC from 1.30 pm to $2.30 \mathrm{pm}$ (a) Variation of CT and DT with load; (b) Variations of NC with load.

At the noon, due to high temperature of external environment, it is observed that the C.T. and D.T. are fluctuating. Though due to well ventilation C.T. does not exceed $62{ }^{\circ} \mathrm{C}$ and D.T. does not exceed $38^{\circ} \mathrm{C}$.

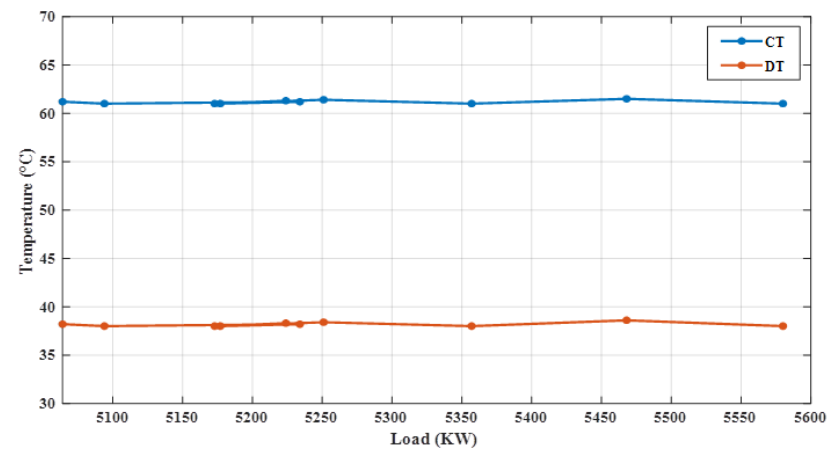

(a)

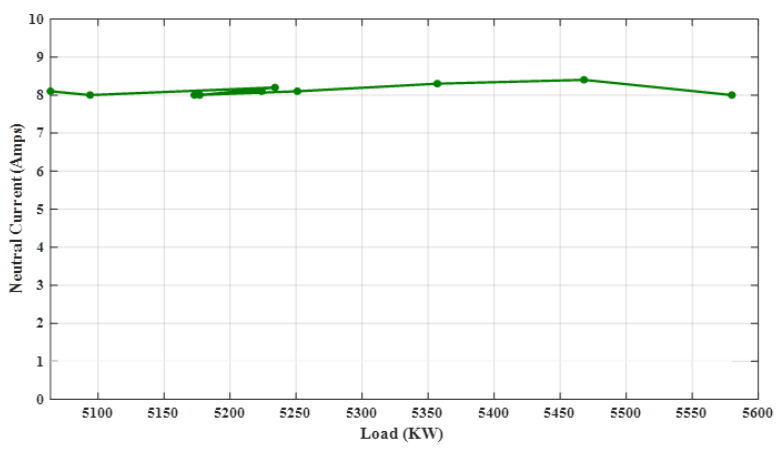

(b)

Fig. 4. This is a figure showing parameters like CT, DT, and NC from 3.30 pm to $4.30 \mathrm{pm}$ (a) Change of CT and DT with load; (b) Change of NC with load.

At the afternoon, though the temperature of external environment is decreasing but generators are running for long time. So, it is observed that the C.T. and D.T. are little bit high. Though due to well ventilation and cooling system C.T. does not exceed $62{ }^{\circ} \mathrm{C}$ and D.T. does not exceed $38.6^{\circ} \mathrm{C}$.

\section{DISCUSSION}

A Zig-Zag transformer is used to compensate for the neutral current. The neutral current and zero sequence components tend to rise with these high-rated KVA configurations. However, by employing this Zig-Zag transformer, the neutral current will be kept below $8.5 \mathrm{Amp}$. Neutral current varies very little as a function of load. Sometimes it was accurately near $7 \mathrm{Amp}$ and some other times its fluctuating in between 7 to $8.5 \mathrm{Amp}$. So, these show that the neutral current is minimized in an optimal condition with these high rated KVA generators. Fig. 5, 6 and 7 show the condition of neutral current after minimization. It seems at the morning time; it is at a constant level but after the increasing of running time and load it tends to rise. Though it is minimized and kept below 8.5 Amp.

\section{CONCLUSION}

It is shown that by constructing an efficient electric power generating system, it is possible to meet some of the electrical power requirements while minimizing neutral current Installations of zig-zag transformers improve the performance of the neutral current in unbalanced loads in applications where active electrical power supply is critical. The cost-effectiveness of utilizing a zig-zag transformer as a neutral current compensator makes it a viable option for small and medium businesses. The neutral current is corrected, and the value of neutral current is reduced up to $8.5 \mathrm{Amp}$. in unbalanced load conditions by using the Zig-Zag transformer, and the power quality is enhanced. The proposed system has a capacity of roughly $6 \mathrm{MW}$ and can be developed to a plant with a higher capacity. Furthermore, the current system will be compatible with future generators, and proper fuel supply and air intake should be considered when installation.

\section{REFERENCES}

[1] Haes Alhelou H, Hamedani-Golshan ME, Njenda TC, Siano P. A survey on power system blackout and cascading events: Research motivations and challenges. Energies. 2019 Jan;12(4):682 https://doi.org/10.3390/en12040682.

[2] Jordehi AR. Optimisation of demand response in electric power systems: a review. Renewable and Sustainable Energy Reviews. 2019 April;103:308-319. https://doi.org/10.1016/j.rser.2018.12.054.

[3] Deng R, Yang Z, Chow MY, Chen J. A survey on demand response in smart grids: Mathematical models and approaches. IEEE Transactions on Industrial Informatics. 2015 Mar 18;11(3):570-582. https://doi.org/10.1109/TII.2015.2414719.

[4] Good N, Ellis KA, Mancarella P. Review and classification of barriers and enablers of demand response in the smart grid. Renewable and Sustainable Energy Reviews. 2017 May 1;72:57-72. https://doi.org/10.1016/j.rser.2017.01.043.

[5] Meng FL, Zeng XJ. A profit maximization approach to demand response management with customers behavior learning in smart grid. IEEE Transactions on Smart Grid. 2015 Aug 14;7(3):1516-1529. https://doi.org/10.1109/TSG.2015.2462083.

[6] Parvania M, Fotuhi-Firuzabad M, Shahidehpour M. ISO's optima strategies for scheduling the hourly demand response in day-ahead markets. IEEE Transactions on Power Systems. 2014 Apr 29;29(6):2636-2345. https://doi.org/10.1109/TPWRS.2014.2316832. 
[7] Nguyen DT, Negnevitsky M, de Groot M. Market-based demand response scheduling in a deregulated environment. IEEE Transactions on Smart Grid. 2013 May 30;4(4):1948-1956. https://doi.org/10.1109/TSG.2013.2258410.

[8] Reka SS, Ramesh V. Demand response scheme with electricity market prices for residential sector using stochastic dynamic optimization. In2016 Biennial International Conference on Power and Energy Systems: Towards Sustainable Energy (PESTSE) 2016 Jan 21 (pp. 16). IEEE.

[9] Kamyab F, Amini M, Sheykhha S, Hasanpour M, Jalali MM. Demand response program in smart grid using supply function bidding mechanism. IEEE Transactions on Smart Grid. 2015 May 25;7(3):1277-1284. https://doi.org/10.1109/TSG.2015.2430364.

[10] Yaghmaee MH, Leon-Garcia A, Moghaddassian M. On the performance of distributed and cloud-based demand response in smart grid. IEEE Transactions on Smart Grid. 2017 Mar 28;9(5):5403-5417. https://doi.org/10.1109/TSG.2017.2688486.

[11] Hoque MN, Mitul AF, Rafi FH, Hasnaine HM. Design of efficient power generation system in medium load industry. In International Conference on Mechanical, Industrial and Energy Engineering 2012.

[12] Bauer M, Plappert W, Wang C, Dostert K. Packet-oriented communication protocols for smart grid services over low-speed PLC. In 2009 IEEE International Symposium on Power Line Communications and Its Applications 2009 Mar 29 (pp. 89-94). IEEE. https://doi.org/10.1109/ISPLC.2009.4913410.

[13] Prasanna GS, Lakshmi A, Sumanth S, Simha V, Bapat J, Koomullil G. Data communication over the smart grid. In 2009 IEEE International Symposium on Power Line Communications and Its Applications 2009 Mar 29 (pp. 273-279). IEEE https://doi.org/10.1109/ISPLC.2009.4913442.

[14] Peres W, Júnior IC, Passos Filho JA. Gradient based hybrid metaheuristics for robust tuning of power system stabilizers. International Journal of Electrical Power \& Energy Systems. $2018 \mathrm{Feb}$ 1;95:47-72. https://doi.org/10.1016/j.ijepes.2017.08.014.

[15] Rahmatian M, Seyedtabaii S. Multi-machine optimal power system stabilizers design based on system stability and nonlinearity indices using Hyper-Spherical Search method. International Journal of Electrical Power \& Energy Systems. 2019 Feb 1;105:729-740. https://doi.org/10.1016/j.ijepes.2018.09.024.

[16] Lobo F, Cabello A, Lopez A, Mora D, Mora R. Distribution network as communication system. In CIRED Seminar 2008: Smart Grids for Distribution 2008 Jun 23 (pp. 1-4). IET.

[17] McGranaghan M, Von Dollen D, Myrda P, Gunther E. Utility experience with developing a smart grid roadmap. In2008 IEEE Power and Energy Society General Meeting-Conversion and Delivery of Electrical Energy in the 21st Century 2008 Jul 20 (pp. 1-5). IEEE.

[18] Kabir MA, Sajeeb MM, Islam MN, Chowdhury AH. Frequency transient analysis of countrywide blackout of Bangladesh Powe System on 1st November, 2014. In 2015 International Conference on Advances in Electrical Engineering (ICAEE) 2015 Dec 17 (pp. $267-$ 270). IEEE. https://doi.org/10.1109/ICAEE.2015.7506847.

[19] Singh B, Jayaprakash P, Kothari DP. A T-connected transformer and three-leg VSC based DSTATCOM for power quality improvement. IEEE transactions on power electronics. 200.8 Dec 9;23(6):27102718. https://doi.org/10.1109/tpel.2008.2004273

[20] Singh B, Solanki J. Load compensation for diesel generator-based isolated generation system employing DSTATCOM. IEEE Transactions on Industry Applications. 2010 Nov 9;47(1):238-244. https://doi.org/10.1109/TIA.2010.2090847.

[21] Jou HL, Wu KD, Wu JC, Chiang WJ. A three-phase four-wire power filter comprising a three-phase three-wire active power filter and a zigzag transformer. IEEE Transactions on Power Electronics. 2008 Jan 4;23(1):252-259. https://doi.org/10.1109/TPEL.2007.911779.

[22] Pirzad Mashak N, Askarzadeh G. Power Quality Improvement with TConnected Transformer and Three-leg VSC Based DSTATCOM SRPH Journal of Interdisciplinary Studies. 2019 Dec 10;1(1):1-10.

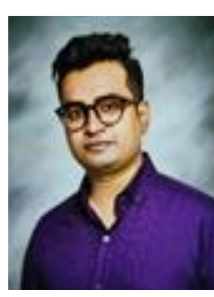

Md. Janibul Alam Soeb is an assistant professor at Sylhet Agricultural University's Faculty of Agricultural Engineering and Technology's Department of Farm Power and Machinery. He earned his M. Sc. in Optics and Photonics from the Karlsruhe Institute of Technology in Germany and the University of Aix Marseille in France. He received his Bachelor of Science in Electrical and Electronic Engineering from the University of Dhaka in Bangladesh. He is particularly interested in renewable energy, nonlinear optics, attosecond science, and laser technology.

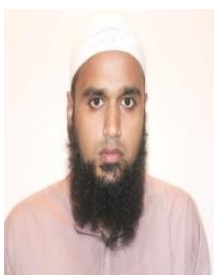

Md. Shahid Iqbal is an Assistant Professor at Sylhet Engineering College in Bangladesh, where he teaches Electrical and Electronic Engineering. He earned his M. Sc. in electrical and electronic engineering from Dhaka University of Engineering and Technology, and his B. Sc. in electrical and electronic engineering from Khulna University of Engineering and Technology, both in Bangladesh. Artificial intelligence, machine learning, and renewable energy are among his research

interests.

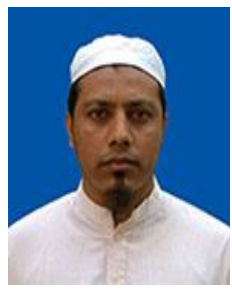

Md. Abu Naser Mojumder is an Assistant Professor in the Computer Science and Engineering Department at Sylhet Engineering College in Bangladesh. $\mathrm{He}$ earned his M. Sc. in Computer Science and Engineering from Islamic University in Bangladesh and his B. Sc. in Computer Science from Daffodil International University in Bangladesh. His areas of interest in research include artificial machine learning, natural language processing, and renewable

energy.

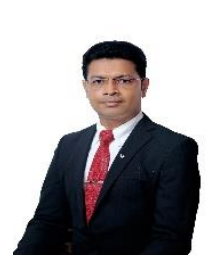

Muhammad Rashed Al Mamun, PhD, was born in the Bangladeshi city of Kaliganj in the province of Gazipur. Dr. Al Mamun graduated from Bangladesh Agricultural University in Mymensingh, Bangladesh, with a B.Sc. in Agricultural Engineering and an MS in Farm Power and Machinery. Dr. Al Mamun is currently a Professor of Farm Power and Machinery at Sylhet Agricultural University in Bangladesh's Faculty of Agricultural Engineering and Technology in Sylhet, Bangladesh. He also served as a VISITING Professor at Kumamoto University, Shahjalal University of Science and Technology, Forestry Science and Technology School, and Agricultural Training Institute Kumamoto University in Japan awarded him a $\mathrm{PhD}$ in Advanced Technology. Dr. Al Mamun also worked as a Research Scientist in Kumamoto University's Ground Water Leadership Program for saving clean ground water. He has received the President Award from Kumamoto University and the Best Publication Award from Sylhet Agricultural University. He's also been given the title of "Kingdom of Saudi Arabia for Environmental Management in the Islamic World." He received the "Venus International Research Award for Outstanding Scientist in Farm Power and Machinery" recently. Dr. Al Mamun is currently working on a number of research projects in Sylhet City Corporation, including agricultural mechanization, tea processing technology, the development of an efficien co-digestion mixing ratio for biogas production using biodegradable material and rumen digesta, the development of cost-effective biogas purification technologies, and solid waste management challenges. Renewable energy, agricultural machinery, precision agriculture, remote sensing, groundwater hydrology, waste management, and GIS-based agricultural policy management for sustainable agriculture in rural regions are all areas of research that he is interested in. Dr. Al Mamun is a member of the Bangladesh Engineering Institute (IEB), the Bangladesh Krishibid Institute (KIB), and the Asia-Pacific Chemical, Biological, and Environmental Engineering Society (APCBEES).

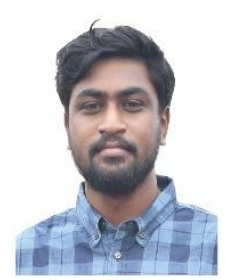

A. S. M. Shahjalal Atik graduated from Sylhet Engineering College in Bangladesh with a B. Sc in Electrical and Electronic Engineering. He is currently employed as a research assistant at Sylhet Agricultural University, Bangladesh. Renewable energy, optical communication, and materials science are among his research interests.

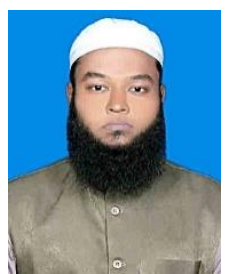

M. F. Jubayer, date of birth: 01/01/1991, place of birth: Bogura, Bangladesh, obtained his MS in Food Engineering (2014) and BSc Food Engineering (2012) from Bangladesh Agricultural University, Mymensingh, Bangladesh. He is currently working as Assistant Professor in the Department of Food Engineering and Technology, Sylhet Agricultural University, Sylhet, Bangladesh. He formerly worked 
for Dan Cake Bangladesh as a Senior Quality Assurance Executive for long 2.5 years. He has more than 25 scientific articles published in national and international journals that include research articles, reviews, correspondence, short-communications, and book chapters. His research interests include food safety, food technology, medicinal plants, and public health. M. F Jubayer is a member of Krishibid Institution Bangladesh, a body for professional agriculturists in Bangladesh. 